\title{
Research into optimization model for balancing the technological flows at mining enterprises
}

\author{
Andrii Khorolskyi $^{1 *}$, Volodymyr Hrinov ${ }^{1}$, Oleksandr Mamaikin $^{2}$, and Liudmyla Fomychova ${ }^{2}$ \\ ${ }^{1}$ Institute for Physics of Mining Processes the National Academy of Sciences of Ukraine, \\ 2A Simferopolska St., 49005 Dnipro, Ukraine \\ ${ }^{2}$ Dnipro University of Technology, 19 Yavornytskoho Ave., 49005 Dnipro, Ukraine
}

\begin{abstract}
The purpose of this paper is to develop new approaches for optimizing the technological flows at coal mines. Based on analysis, the area of the presented approaches application has been outlined for decision-making in mining. The concept is to use graph theory methods and network models for balancing the flows incoming to the mine in the form of resources and the output flows in the form of coal, rock, gas, and water. This improves the overall efficiency of functioning the mining enterprise. A new model is proposed that describes the production activity of the underground mining complex for the delivery of three production components to the surface. These components from the viewpoint of rational resource and environmental management can be considered as factors that may have a negative impact on the level of technological scheme in terms of investing advisability, as well as on the environment. These components are coal, rock, methane gas and mine water. Given their stochastic nature, it is accepted for the mathematical description of the movement processes of coal $(C)$, rock $(R)$, methane gas $(G)$ and water $(W)$ to represent them in the form of flows within some technological system of converters, and including the diversification of mining production. The presented approach can be applied not only at the stage of designing, but also to assess the existing state of the coal mines. Special attention is focused on the development of software for decision-making.
\end{abstract}

\section{Introduction}

The general tendencies as a consequence of crisis phenomena in the global coal industry present new challenges associated not with increasing output or increasing income, but, above all, with maintaining of the enterprise functioning. This is conditioned by the fact that the coal industry requires a large amount of resources, and at the stage of designing, it is necessary to take into account parameters that are not completely interrelated. What is more, a problem exists that the mine at the stage of designing is considered as a coal mining enterprise, and not as a link in the system of electrical energy and metal generation. At the same time, the mine itself is a consumer of these resources. It would be expedient, in order to overcome most of the negative phenomena, to balance the flows of incoming resources

\footnotetext{
*Corresponding author: andreykh918@gmail.com
} 
in the form of materials, equipment, as well as the output resources in the form of finished products. Thus, not only coal, but also by-products in the form of rocks, gas and water should be taken into account in the proposed model. This will allow to comprehensively consider the problem of searching for the optimal solution at the stage of designing, as well as when assessing the prospects of a coal enterprise. Moreover, a specific mine should be considered as a link in the "coal-coke-metal" or "coal-electrical energy" system. The technological flows of coal mines have a significant impact on the environment, which is also important and also worth considering. The above problems require answers to questions: - What should be done to stabilize the state of coal enterprise? How to balance the technological flows of the enterprise? What tools and what is the procedure for implementing? The answers to these questions will be presented in this research.

The research relevance is conditioned by the following problems:

- a number of parameters, not interrelated with each other, influence on the overall enterprise efficiency. Furthermore, the number of these parameters, even within the framework of one system or process, exceeds several tens;

- at the decision-making stage, the obtained answer can be either quantitative (producing costs, productivity, time expenditure, etc.) or qualitative (degree of advantage, degree of "desirability"), etc. Therefore, it is necessary to determine the main criterion of effectiveness;

- regardless of the used approach, there is a need for decision-making ways, as well as for creating a "bank of design decisions".

Thus, from the relevance of research, the following requirements arise to the approach universality, a definite answer, and the possibility of implementation.

Conventionally, decision-making approaches in mining can be divided into information and optimization [1]. They are distributed on the basis of final result. The information approach answers the question - which solution is the most preferable and is based on expert assessments. The optimization approach answers the question - which solution is the most appropriate from an economic or technological point of view. Among the information approaches, the most widespread at the decision-making stage in mining practice are the methods of multi-criteria optimization MCDMA based on the analysis of hierarchies AHP (Analytic Hierarchy Process) (Kursunoglu N., Onder M. [2], Ataei, M. [3]) and their variations PROMETHEE (Bogdanovic D. [4]), ELECTRE (Iphar M. [5]), VIKOR (Hayati M. [6]), Grey-AHP (Huang, W. [7]), Fuzzy-AHP (Naghadehi, M. Z. [8]), WPM (Balusa B. C. [9]). Each of the above approaches [2 - 9] provides for the selection of criteria at the stage of designing, conducting an expert assessment and comparing options among themselves. The result is an answer to the question which of the solutions is preferred, but it is not known how much it will be "preferable" if there are other optimality criteria. There is also the subjectivity problem at the assessment stage. Besides, the correlation between the prevailing and unacceptable decision is not always proportional [10]. The above group of approaches [2-9] is effective at the stage of designing, but more "sensitive" tools should be used for existing enterprises.

Optimization approaches are divided, first of all, in accordance with the objective function of the criteria, into mathematical programming methods, which are differentiated with respect to the decision-making procedure into linear [11], quadratic [12], integer [13], geometric [14], stochastic [15], and dynamic [16] programming; deterministic models, probabilistic models. If the methods of mathematical programming answer to the question which solution is optimal, then deterministic models demonstrate the correlation between the parameters, forming the method of displaying - whether they are correlation relations [17-20] or graphical [10,21]. Probabilistic models are based on the concept of "reliability" [20], that is, the ability of the system to reproduce a specified level of productivity over time in accordance with the accepted restrictions. 
The group of optimization approaches $[11-21]$ is effective at the stage of operating management by production activity. However, it is necessary from this variety to choose the most preferable in terms of its visualization possibility, as well as the formation of a "bank of design decisions". In our opinion, graphs and network models can be used for it [22]. There are a few advantages - visualization, simplicity, the possibility of implementation on all platforms, versatility, the ability to form a "bank of design decisions". In addition, the very definition of "graph" and "network model" already implies structuring and ordering, and this is the main requirement at the stage of management by technological flows. Thus, it is necessary to develop a model that takes into account the correlation of technological flows, and also to propose an approach to decision-making. The solutions to these issues are covered in this paper.

\section{Methods}

As known, the result of the production activity of the underground mining complex is the delivery to the surface of three production components. These components from the viewpoint of rational resource and environmental management can be considered as factors that may have a negative impact on the investing advisability. These components are coal, rock, methane gas and mine water. Given their dynamic nature, it is expedient for the mathematical description of the movement processes of coal $(C)$, rock $(R)$, methane gas $(G)$ and water $(W)$ to represent them in the form of flows within some technological system of converters. At the same time, conversion is aimed at obtaining the basic and additional raw materials resources, as well as minimizing the environmental damage [16].

The main method for studying the model is the method of multivariate statistical analysis. With account of these requirements, the following designations are introduced

$$
K_{e}=\left\{\frac{D_{p i}}{D_{D i}}, \frac{\alpha_{D i}}{\alpha_{p i}}, \frac{\sum P_{i}}{\sum Z_{i}}, \frac{V_{P i}}{V_{i}}, \frac{\sum Z_{P i}}{\sum Y_{P i}}, \frac{Q_{B i}}{Q_{i}}, \frac{\sum Z_{B i}}{\sum Y_{\ni i}}, \frac{D_{B i}}{V_{i}}\right\},
$$

where $\alpha$ is coal quality indicator (ash-content), $\%$;

$$
K_{F i}=\left\{Z_{i 1}, Z_{i 2}, Z_{i 3}, Z_{i 4}, Z_{i 5}, Z_{i 6}, Z_{i 7}, Z_{i 8}\right\},
$$

where $K_{F \mathrm{i}}$ is stability characteristic of each diagnostic feature; $Z_{i j}$ is stability factor of the $i$-th feature, determined as the variation coefficient of the output flow parameter, which is a component of $K_{F i}$.

Thus, the effective feature for the $i$-th mine can be represented by substituting (1) in (2):

$$
K_{e}=\left\{\frac{D_{p i}}{D_{D i}} Z_{i 1}, \frac{\alpha_{D i}}{\alpha_{p i}} Z_{i 2}, \frac{\sum P_{i}}{\sum Z_{i}} Z_{i 3}, \frac{V_{P i}}{V_{i}} Z_{i 4}, \frac{\sum Z_{P i}}{\sum Y_{P i}} Z_{i 5}, \frac{Q_{B i}}{Q_{i}} Z_{i 6}, \frac{\sum Z_{B i}}{\sum Y_{Э i}} Z_{i 7}, \frac{D_{B i}}{V_{i}} Z_{i 8}\right\} .
$$

Expression (3) makes it possible to take into account the technological flows stability, as well as the quality of products produced by the mine.

In order to compare the result of a certain parameter action on the volume, the values of $X_{i j}$ are brought in the matrix in the form of standardized features. Standardization is conducted by generally accepted methods using arithmetic mean values and mean-square deviations.

From viewpoint of integrated assessment of the mines productivity, the production volume plays a very important role, but not decisive. This is especially evident in the qualitative coal characteristics, therefore, in the volume of marketable products and the ratio of produced and processed (left in the mine) rocks. Unfortunately, in recent years, 
parallel methane extraction has not been carried out. This fact does not increase the rating of technological schemes of the regional mines.

The input parameters, external conditions of such a system are as follows.

For flow C (coal):

$D_{i}-$ output volume of each i-th mine with account of expenses, tons/year;

$D_{m}$ - volume of marketable products, tons/year;

$A_{i}-$ quality of mined coal (ash-content), \%;

For flow R (rock):

$V_{i}$ - rock volume that is delivered to the surface, tons;

$V_{n}$ - rock volume that is processed, tons.

For flow $G$ (gas):

$Q_{i}$ - predicted (possible) methane yield, $\mathrm{m}^{3} /$ year;

$Q_{n}$ - amount of methane that is processed, $\mathrm{m}^{3} /$ year.

The objective function of such a system is output parameters maximization (relations of conversions) with their optimal distribution within the system (relations of correlations).

The optimality condition for the relation of conversions:

$$
K_{o p}=\max \{D, A, V, Q\} .
$$

In addition, as mentioned above, to study the relations of correlation, they should be optimized, which in the particular case is the task of finding the optimal distribution of coal flows between mines and beneficiation plants.

Given the above conditions, the basic requirements can be formulated for the model which is being formalized:

- the model solution should allow comparing the performance of all mines in the region;

- a complex indicator of economic $K_{e}$ and functional $K_{F}$ efficiency is used as a performance criterion:

$$
x_{i}=K_{e} \cdot K_{F_{i}},
$$

where $i=1,2, \ldots, m$ is mine index (order number).

The indicator $K_{e}$ should take into account the maximizing condition of the output parameters of the flows $C, R, G$.

The indicator of functional efficiency $K_{F i}$ should represent the characteristic of the system operable state. The main method for model study is the method of multivariate statistical analysis.

Given these requirements, the following designations are introduced:

$$
\begin{gathered}
K_{e i}=\{D, A, V, Q\} ; \\
K_{F_{i}}=\left\{Z_{i 1}, Z_{i 2}, Z_{i 3}, Z_{i 4}, Z_{i 5}, Z_{i 6}, Z_{i 7}\right\},
\end{gathered}
$$

where $K_{F i}$ is characterizes each diagnostic feature stability; $Z_{i j}$ is stability factor of the $i$-th feature, determined as the variation coefficient of the output flow parameter, which is a component of $K_{e i .}$.

Thus, the effective feature for the $i$-th mine of the region can be represented as follows:

$$
x_{i}=\{D, A, V, Q\} \times\left\{Z_{i 1}, Z_{i 2}, Z_{i 3}, Z_{i 4}, Z_{i 5}, Z_{i 6}, Z_{i 7}, Z_{i 8}\right\} .
$$

The procedure of multivariate comparative analysis begins with the initial matrix formation in the form: 


$$
X=\left[\begin{array}{cccc}
x_{11}, & x_{12}, & \ldots, & x_{1 n} \\
x_{21}, & x_{22}, & \ldots, & x_{2 n} \\
x_{m 1}, & x_{m 2}, & \ldots, & x_{m n}
\end{array}\right],
$$

where $i$ is mine index $(i=1,2, \ldots, m) ; k$ is index of a certain parameter $(k=1,2, \ldots, n) ; x_{i j}$ is value of the $j$-th parameter for the $i$-th mine.

In order to compare the result of a certain parameter action on the volume, the values of $x_{i j}$ are brought in the matrix in the form of standardized features. Standardization is conducted by generally accepted methods using arithmetic mean values and mean-square deviations [23].

An important step in processing the adjusted $x_{i j}$ values is to differentiate them with respect to importance using hierarchy coefficients. Estimation algorithm is as follow:

1. Firstly, the diagnostic features of mines (coal output, the amount of rock, gas, methane) should be brought in one matrix. The indices of diagnostic features $k$ take the following values: annual coal output in mine 1, volume of marketable products 2 , rock mass ash-content 3, rock volume that is delivered 4, volume of the processed rock 5, volume of methane use 6 , environmental expenditure ratio 7 , volume of used mine water 8 . For the selected set of mines, 4 features are chosen, since no significant operations are yet being conducted in the direction of using methane or mine water.

2. For ability to compare the values of various diagnostic features among themselves, they must be converted to the same dimensionality. To do this, the so-called "standardization" should be performed, as a result of which the values of the features are expressed in fractions of the mean-square deviations.

$$
z_{i k}=\frac{x_{i k}-\bar{x}_{k}}{s_{k}},
$$

where $x_{i k}$ is diagnostic feature value $k$ for the mine $i ; \bar{x}_{k}$ is arithmetic mean value of the diagnostic feature $k$ is determined by the formula:

$$
\bar{x}_{k}=\frac{\sum_{i=1}^{w} x_{i k}}{w},
$$

where $S_{k}$ is standard deviation of the diagnostic feature $k$ is determined by the formula:

$$
s_{k}=\left[\frac{1}{w} \sum_{i=1}^{w}\left(x_{i k}-\bar{x}_{k}\right)^{2}\right]^{1 n} .
$$

In order to use the adjusted standardized values of diagnostic features, they are differentiated with respect to their importance (according to their influence on the deviation of diagnostic features values of the analyzed mines) using the so-called hierarchy coefficient. For this purpose, a matrix of distances between the diagnostic features is formed, the elements of which characterize the averaged deviation of the diagnostic feature $k$ from the feature $l$, calculated by the formula:

$$
b_{k l}=\left[\frac{1}{w} \sum_{i=1}^{i w}\left(z_{i k}-z_{i l}\right)^{2}\right]^{\frac{1}{2}},
$$

where $k, l=1 / n$ is diagnostic features index; $z_{i k}, z_{i l}$ are standardized value of the diagnostic 
feature $k$ and $l$ for the mine $i$, respectively.

The standardized value of the mine-standard diagnostic features is characterized by the best values of the diagnostic features at the analyzed enterprises. The choice of feature values for the mine-standard depends on the nature of its impact on the result of the mine production activity. For example, for indicators of rock mass ash-content, for coal and rock output ratio, their minimum values are chosen.

The deviation of the diagnostic features value of the mine $i$ from the corresponding values of the mine-standard diagnostic features $\rho_{\mathrm{i}}$ is determined as follows:

$$
\rho_{i 0}=\left[\sum_{\pi=1}^{m}\left(z_{i k}^{\prime}-z_{0 k}^{\prime}\right)^{2}\right]^{\frac{1}{2}} .
$$

Then, the arithmetic mean value is found of the diagnostic features deviation of the mines from the corresponding values of the mine-standard diagnostic features.

$$
\overline{\rho_{0}}=\frac{1}{w} \sum_{i=1}^{w} \rho_{i 0} .
$$

The differential in the deviation values of the diagnostic features from the values of the mine-standard diagnostic features is characterized by a standard deviation.

$$
S_{0}=\left[\frac{1}{w} \sum_{i=1}^{w}\left(\rho_{i 0}-\overline{\rho_{0}}\right)^{2}\right]^{\frac{1}{2}} .
$$

The maximum permissible value of the diagnostic features deviation for all mines is determined:

$$
\rho_{0}=\bar{\rho}+2 S_{0} .
$$

Ultimately, the mine state indicator is found by the formula:

$$
d_{i}=\frac{\rho_{i 0}}{\rho_{0}} .
$$

The closer this indicator is to unity, the greater the deviations of the diagnostic feature values of the mine $i$ from the mine-standard diagnostic features. That is, the physical significance of the quantitative assessment is as follows - the indicators of production activity in dimensionless characteristics tend to zero, thereby achieving stability of activity. This is realized by means of the greater involvement of the enterprise in the regional economy, as well as the system for generating energy, metal, etc.

\section{Results and discussion}

From the above model it can be seen that to balance the flows, it is necessary to the full use the mine potential. This is realized by analyzing the ratios in the "coal-coke-metal" or "coal-beneficiation plants - electrical energy" chains. The actual structure of "coalelectrical energy" relations in the Donetsk region, as well as "coal - coke - metal" relations have been built [24]. The presented models reflect the quantitative ratio of mines $S_{n}$ producing the coal of grades $M_{n}$, beneficiation plants $V_{n}$ and power plants $E_{n}$. 


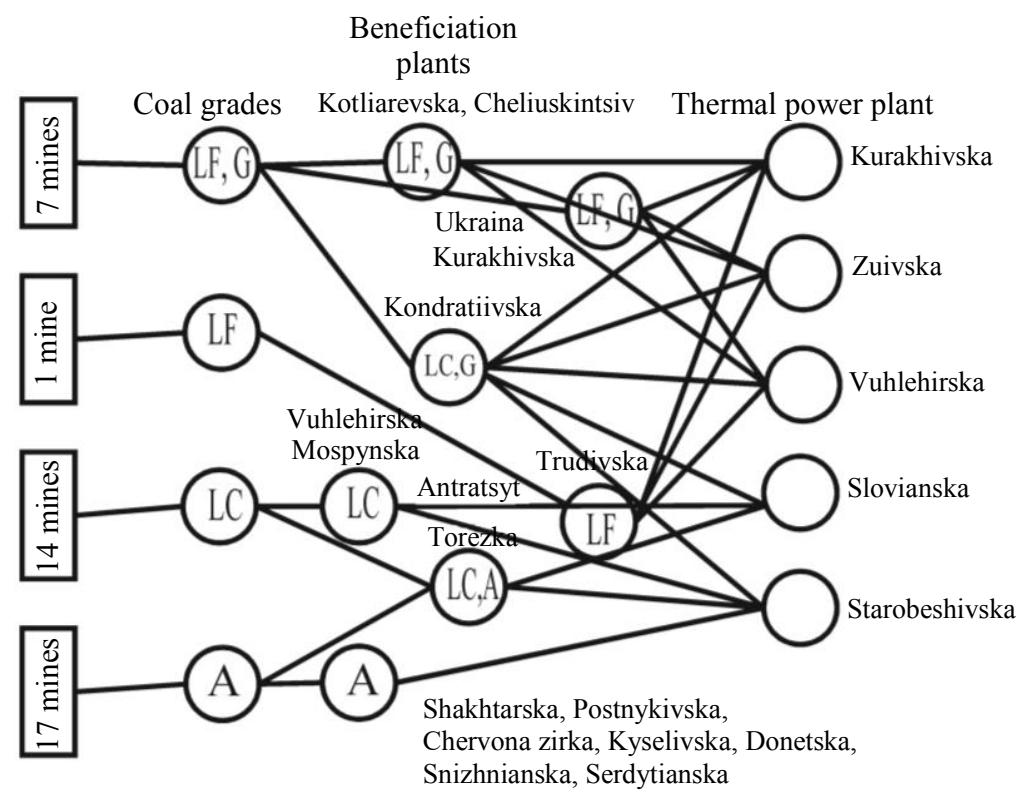

Fig. 1. The actual structure of "coal-electrical energy" relations in the Donetsk region.

Then, to find the optimal relations in the "coal-electrical energy" system, each apex should be numbered, and the network model edges (lines connecting the apexes) must be assigned a parameter value, after which the network model should be optimized. To do this, it is necessary:

- denote the network model apexes as "not painted", that is, the distance from the first apex to the others is not determined; as the shortest routes between the apexes are found, they will be "painted over", that is, they will be excluded from further calculations;

- after this, it is necessary to search for the shortest route between the apexes $(i, j)$, to which a value $d(x)$ is assigned. Thus, the shortest route from point $i$ to point $j$ is found;

- suppose that $d(i)=0 ; d(x)=\infty$, that is, if the shortest route between the points $(i, j)$ is found, then the length of the route from the point $j$, corresponding to the order number of the optimal apex, to the point $i$, corresponding to the initial apex, is equal to $d(x)$, and to other apexes (not optimal) is equal to $d(x)=\infty$;

- in a similar way let us determine the distance between other points, taking into account the previously found shortest route $d(x): d(x)=\min \{d(x), d(y)+a(y, x)\}$, where $d(y)$ - the last apex for which the shortest route is found, $a(y, x)$ - parameter value;

- in this case, when the order number of the apex $y$, to which the optimal route should be found, is equal to $y=t$, where $t$ is number of apexes, the calculations should be completed. The "coal mine-beneficiation plant-power plant" optimal structure has been obtained with the smallest value of the parameter, which should be minimized.

The situations studied in this paper and their solutions are interpretations of already known dynamic programming problems [25]. However, with the information technology development, it is possible to obtain new algorithms for approximate and accurate calculation methods, as well as significantly increase the tasks dimensionality.

The methodology presented in this paper is universal and can be applied not only to solve the problem of stabilizing the regional industry state, but also when organizing transportation between enterprises to reduce the cost of equipment repair and 
maintenance, etc. However, when applying manual search or linear programming methods, the search process is complicated by a large tasks dimensionality. As a consequence, time expenditure increases and it is also difficult to interpret the result from the matrix representation in a form understood by a designer. That is why the corresponding software has been developed at the Institute for Physics of Mining Processes (Fig. 2), which makes possible to automate the search for optimal relations, increase the tasks dimensionality, interpret results, and create reports [26].

Further application of methods in networks and graphs gives an ability to find the structure of coal and electrical energy production at the lowest cost.

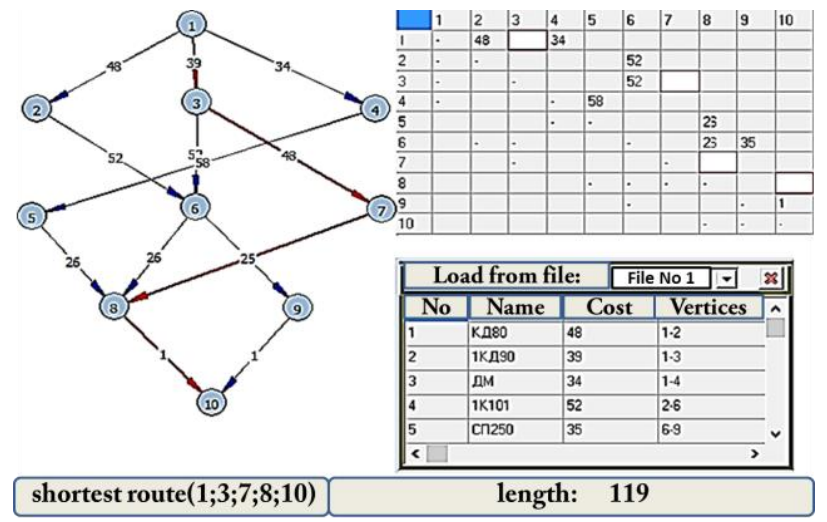

Fig. 2. Fragment of the program work window.

Thus, the model proposed in the paper takes into account the correlation between the flows of incoming and output resources in the "coal-electrical energy" system using decomposition methods that take into account the relations between mines and beneficiation plants, between beneficiation plants and power plants, as well as between mines and power plants [27-32].

\section{Conclusions}

As a result of reseach, it has been revealed that for the efficient enterprise operation and to maintain the enterprise functioning, it is necessary to balance the technological flows of coal mines. This comprises an integrated accounting of coal mining, production of rocks, extraction of methane gas and water. To solve this problem, a complex criterion is proposed that includes the following components:

1. The ratio of mined coal and marketable coal. It characterizes not only the qualitative characteristics of coal and the need for it in the market, but also the sale activities at the enterprise. Ideally, this parameter should approach unity.

2. It should be noted that the most important indicator characterizing the coal quality is its ash-content. In this regard, the model proposes the ash-content ratio of the mined coal and the ash-content of sold coal.

3. The integrated natural resources use is very important during the process of mines restructuring. For the mines of this region, a ratio is introduced of rock volumes, which are delivered from the mines, and the part that the mine processes for backfilling, manufacturing of building materials and the like.

Improvement of the enterprise performance is ensured by a comprehensive consideration of the mine activity as a component in the "coal-coke-metal" or "coal- 
beneficiation plant-electrical energy" chain. This will allow organizing industrial relations in the region and improving the quality of the final product in the form of electrical energy and metal.

To improve the quality of extracted raw materials and reduce unit costs, it is necessary to use network models and graphs, and the use of the software described in the paper enables automation of the decision-making process.

The study has been carried out within the framework of research project of the NAS of Ukraine for young scientists "Resource-saving techniques to support mine workings under the complex hydrogeological conditions" (State registration No. 0119U102370).

\section{References}

1. Khorolskyi, A., \& Hrinov, V. (2020). Otsinka i vybir parametriv pry rozrobtsi rodovyshch korysnykh kopalyn. Fyziko-tekhnycheskie problemy hornoho proizvodstva, (22), 118-140. https://doi.org/10.37101/ftpgp22.01.009

2. Kursunoglu, N., \& Onder, M. (2015). Selection of an appropriate fan for an underground coal mine using the Analytic Hierarchy Process. Tunnelling and Underground Space Technology, (48), 101-109.

3. Ataei, M., Jamshidi, M., Sereshki, F., \& Jalali, I. (2008). Mining method selection by AHP approach. Journal of the Southern African Institute of Mining and Metallurgy, 108(12), 741-749.

4. Bogdanovic, D., Nikolic, D., \& Ilic, I. (2012). Mining method selection by integrated AHP and PROMETHEE method. Anais da Academia Brasileira de Ciências, 84(1), 219-233.

5. Iphar, M., \& Alpay, S. (2019). A mobile application based on multi-criteria decision-making methods for underground mining method selection. International Journal of Mining, Reclamation and Environment, 33(7), 480-504.

6. Hayati, M., Rajabzadeh, R., \& Darabi, M. (2015). Determination of Optimal Block Size in Angouran Mine Using VIKOR Method. Journal of Materials and Environmental Science, 6(11), 3236-3244.

7. Huang, W. et al. (2015). Stability assessment of underground mined-out areas in a gold mine based on complex system theory. Geotechnical and Geological Engineering, 33(5), 1295-1305.

8. Naghadehi, M.Z., Mikaeil, R., \& Ataei, M. (2009). The application of fuzzy analytic hierarchy process (FAHP) approach to selection of optimum underground mining method for Jajarm Bauxite Mine, Iran. Expert Systems with Applications, 36(4), 8218-8226.

9. Balusa, B., \& Singam, J. (2018). Underground mining method selection using WPM and PROMETHEE. Journal of the Institution of Engineers (India): Series D, 99(1), 165-171.

10. Hrinov, V. \& Khorolskyi, A. (2018). Improving the Process of Coal Extraction Based on the Parameter Optimization of Mining Equipment. E3S Web of Conferences, (60), 00017. https://doi.org/10.1051/e3sconf/20186000017

11. Kulshreshtha, M., \& Parikh J. (2002). Study of efficiency and productivity growth in opencast and underground coal mining in India: a DEA analysis. Energy Economics, 24(5), 439-453.

12. Li, P. et al. (2011). Time series prediction of mining subsidence based on a SVM. Mining Science and Technology, 21(4), 557-562.

13. Bakhtavar, E., Shahriar, K., \& Mirhassani, A. (2012). Optimization of the transition from open-pit to underground operation in combined mining using $(0-1)$ integer programming. Journal of the Southern African Institute of Mining and Metallurgy, 112(12), 1059-1064.

14. Erdogan, G. et al. (2017). Implementation and comparison of four stope boundary optimization algorithms in an existing underground mine. International Journal of Mining, Reclamation and Environment, 31(6), 389-403.

15. Dimitrakopoulos, R., \& Ramazan, S. (2008). Stochastic integer programming for optimising long term production schedules of open pit mines: methods, application and value of stochastic 
solutions. Mining Technology, 117(4), 155-160.

16. Khorolskyi, A., Hrinov, V., \& Kaliushenko, O. (2019). Network models for searching for optimal economic and environmental strategies for field development. Procedia Environmental Science, Engineering and Management, 6(3), 463-471.

17. Fomychov, V., Mamaikin, O., Demchenko, Y., Prykhorchuk, O., \& Jarosz, J. (2018). Analysis of the efficiency of geomechanical model of mine working based on computational and field studies. Mining of Mineral Deposits, 12(4), 46-55. https://doi.org/10.15407/mining12.04.046

18. Saik, P., Petlovanyi, M., Lozynskyi, V., Sai, K., \& Merzlikin, A. (2018). Innovative Approach to the Integrated Use of Energy Resources of Underground Coal Gasification. Solid State Phenomena, (277), 221-231.https://doi.org/10.4028/www.scientific.net/ssp.277.221

19. Sadovenko, I., Inkin, O., Dereviahina, N., \& Hriplivec, Y. (2018). Analyzing the parameters influencing the efficiency of undereground coal gasification. Journal of Geology, Geography and Geoecology, 27(2), 332-336. https://doi.org/10.15421/111857

20. Sadovenko, I., Puhach, A., \& Dereviahina, N. (2019). Investigation of hydrogeomechanical parameters of loess massifs in conditions of technogenic underflooding and development of technical recommendations for strengthening of bases of foundations. Journal of Geology, Geography and Geoecology, 28(1), 173-179. https://doi.org/10.15421/111918

21. Salli, S., Pochepov, V., \& Mamaykin, O. (2014). Theoretical aspects of the potential technological schemes evaluation and their susceptibility to innovations. Progressive Technologies of Coal, Coalbed Methane, and Ores Mining, 491-496. https://doi.org/10.1201/b17547-81

22. Khorolskyi, A., Hrinov, V., \& Mamaikin, O. (2019). Models and methods to make decisions while mining production scheduling. Mining of Mineral Deposits, 13(4), 53-62. https://doi.org/10.33271/mining13.04.053

23. Hrinov, V., \& Khorolskyi, A. (2019). Optymalne proektuvannia parametriv hirnychozbahachuvalnykh pidpryiemstv dlia ratsionalnoho osvoiennia tsinnykh rodovyshch Ukrainy. Fiziko-tekhnicheskie problemy hornoho proizvodstva, (21), 128-145. https://doi.org/10.37101/ftpgp21.01.008

24. Hrinov, V., Khorolskyi, A., \& Mamaikin, O. (2019). Dekompozytsiinyi pidkhid pry pobudovi system heneratsii enerhii u vuhlepromyslovykh rehionakh. Visti Donetskoho Hirnychoho Instytutu, (44), 116-126. https://doi.org/10.31474/1999-981x-2019-1-116-126

25. Bellman, R., \& Dreyfus, S. (1965). Prikladnye zadachi dinamicheskogo programmirovaniya. Moskva: Nauka, 460.

26. Hriniov, V., Khorolskyi, A., \& Kaliushchenko, O. (2019). Rozroblennia ekolohichnykh stsenariiv efektyvnoho osvoiennia tsinnykh rodovyshch korysnykh kopalyn. Mineralni Resursy Ukrainy, (2), 46-50. https://doi.org/10.31996/mru.2019.2.46-50

27. Bondarenko, V., Cherniak, V., Cawood, F., \& Chervatiuk, V. (2017). Technological safety of sustainable development of coal enterprises. Mining of Mineral Deposits, 11(2), 1-11. https://doi.org/10.15407/mining11.02.001

28. Kovalevska, I., Zhuravkov, M., Chervatiuk, V., Husiev, O., \& Snihur, V. (2019). Generalization of trends in the influence of geomechanics factors on the choice of operation modes for the fastening system in the preparatory mine workings. Mining of Mineral Deposits, 13(3), 1-10. https://doi.org/10.33271/mining13.03.001

29. Bondarenko, V., Symanovych, G., \& Koval, O. (2012). The mechanism of over-coal thin-layered massif deformation of weak rocks in a longwall. Geomechanical Processes During Underground Mining, 41-44. https://doi.org/10.1201/b13157-8

30. Yeshchenko, M., Koval, V., \& Tsvirko, O. (2019). Economic policy priorities of the income regulation. Espacios, 40(38), 11.

31. Baklanova, O., Petrova, M., \& Koval, V. (2020). Institutional Transmission in Economic Development. Ikonomicheski Izsledvania, 29(1), 68-91. 